\title{
Use of Cohesive Devices in Children and Regular Literature: Conjunctions and Lexical Cohesion
}

\author{
Mohammad Raouf Moini (Corresponding author) \\ Department of English, University of Kashan, Iran \\ Fateme Kheirkhah \\ Department of English, University of Kashan, Iran
}

Received: 18-08-2016

doi:10.7575/aiac.ijclts.v.4n.4p. 12
Accepted: 23-09-2016

Published: 31-10-2016

\begin{abstract}
Cohesion is an indispensable linguistic feature in any discourse. Lexical Cohesion and conjunction as two crucial elements to textual cohesion and comprehension have been the focus of a wide range of studies up to now. Yet the relationship between the open register and cohesive devices has not been thoroughly investigated in discourse studies. This study concentrates on the potential similarities and differences between literature for children and adult level (regular) with respect to the frequency of lexical cohesive markers and conjunctions. To this end, selected excerpts of two contemporary famous novels were analyzed and codified for the use of different kinds of lexical cohesion (reiteration and collocation), conjunctions (elaboration, extension and enhancement) and their subcategories. The results of Chi square tests showed that the children and regular novel texts were significantly different in terms of reiteration and collocation as the main categories of lexical cohesion as well as total frequency of lexical cohesive pairs. Also, the use of conjunctions, elaboration and extension showed significant difference. Yet, the difference was non-significant for enhancement. The findings of this study add to the existing literature of research on cohesion and inspire researchers in discourse studies, child language studies, and English teaching and learning of young children.
\end{abstract}

Keywords: Cohesive devices, Conjunctions, Lexical Cohesion, Children, Literature

\section{Introduction}

Cohesion system was mainly introduced by Halliday \& Hasan (1976). They argued that cohesion has a semantic concept, which refers to relations of meaning that exist within the text and define it as a text. Halliday (1989) confirms that cohesion occurs where the interpretation of some elements in discourse is dependent on that of another. Cohesive devices or 'cohesive ties' might be grammatical or lexical and consist of words, phrases or clauses that link the discourse items together. As Rahimi and Ebrahimi (2012) argued, analysis of cohesive devices within a text provides more insight into how writers organize what they want to say and maybe crucial to our judgment of whether something is well-written or not. Studying cohesion as an essential part of textual unity can be beneficial for different areas including linguistics, translation and language teaching and learning. Studying the use of different cohesive devices can help second language learners grasp the text structure and improve their reading comprehension, their writing and translation skills. Furthermore, analyzing a text in order to derive the cohesive devices makes one more sensitive to the way in which sentences are related and, ultimately enhances his/her linguistic sense (Lee, 2013).

Lexical cohesion in particular is necessary to give a discourse dimension to vocabulary teaching and vocabulary activities in classroom. "In a discourse based approach, students themselves can be motivated to collect item along discourse functional lines, something that becomes more and more important as they embark on composition writing and argumentation in general." (Rahimi and Ebrahimi.2012, p.2) The study of conjunction as a cohesive device for creating intra sentential and more importantly inter sentential relations in a text and beyond thats also of a great importance. There is compelling evidence implying that children use more connectives in their language as they get older. So, investigating the use and frequency of different kinds of conjunctions for children and adults can open a new line of research in cohesion studies.

Since the introduction of cohesion by Halliday \& Hasan (1976) a number of studies have analyzed the function of cohesion in text and its comprehensibility. Recent studies in this field have mainly been done on grammatical cohesion including reference, substitution, ellipsis, and conjunction of English written texts. e.g., Bennet-Kastor (1986); Coulthard (1994); Gutwinski (1976); Parsons (1996) and Stotsky (1983). In addition, other languages have been analyzed in this respect as well; e.g., Russian in Simmons (1981); English and Hindi in Kachroo (1984); Spanish in Mederos Martín (1988) and Casado Velarde (1997); English and Japanese in Oshima (1988); Persian in Roberts, Barjasteh, Delforooz, \& Jahani (2009). 
Noor-Mohammadi (1984) investigated a contrastive study on the application of cohesion devices in English and Persian. Kavoosi-Nejad (1993) explored ellipsis in noun phrases, verb phrases and sentences, and indicated the differences between ellipsis and substitution. Based on Halliday \& Hasan (1976), Fazl-Ali (1995) explored ellipsis in Persian stories of Al-e-Ahmad and Daneshvar, and revealed that verbal ellipsis is less frequent.

Tseng \& Liou (2006) inquired about the effects of online conjunction materials on college EFL students` writing. They argued that inappropriate utilization of conjunction in English, which leads to incoherent writing, is due to the first language interface, misleading lists of connectors, and improper exercises. They also informed that pedagogical instructions for teaching online conjunction materials would assist EFL learners to have more writings that are coherent.

Roberts et al. (2009) following Dooley \& Levisohn's (2001) analytical methodology described different aspects of discourse analysis including an introductory description of cohesion and coherence in 16 Iranian stories. They have also shown the style of working on discourse studies in Persian language. More recently, Yang \& Sun (2012) explored the use of cohesive devices in argumentative writing by Chinese sophomore and senior EFL learners. The results of analysis revealed that the ellipsis and substitution devices were mostly found in spoken language and were less applicable in formal written discourse.

\section{Literature Review}

Furthermore, many studies have been conducted in the field of language teaching to make a contrastive analysis of the links of textuality or lexical cohesive signals used in various languages (e.g. Zhu, Zheng, \& Miao, 2001; Zhang \& Liu, 2003; Hyland, 2005). A great deal of the studies also made in academic discourse, for example, Kai (2008) conducted a Comparative study on Lexical Cohesion Patterns in NS and NNS Dissertation Abstracts in Applied Linguistic based on Hoey's (1991) model. The study showed that NS abstracts tend to use more complex repetitions than NNS ones, which have a high rate of using simple repetitions. Another finding was that the patterning of lexical repetition in the sample texts could take a central place in the organization and understanding of dissertation abstracts. MacMillan (2007) conducted a project in which it was found that lexical cohesion played a basic role in reading comprehension sections of different types (paper-based, computer-based or internet-based) of TOEFL tests.

In another research, Seddigh, Shokr Pour, and KafiPour (2010) analyzed lexical cohesion in English and Persian abstracts. All sub-types had nearly the same occurrences in the two sets of data and the two-tailed t-test revealed that the differences between their applications in English and Persian abstracts are not statistically significant. Both languages reported repetition as the most frequent sub-type, but synonymy and meronymy were the least used sub categories. Mirzapour and Ahmadi (2011) compared the use of lexical devices in English and Persian research articles published in literature and linguistics. Analyzing 60 research articles, 30 from each language, they found that the most frequent lexical cohesive markers employed in both sets of texts were repetition, collocation, and synonymy, respectively.

Also, among researchers on media discourse, Gonzalez study (2011) highlights the difference between 'associative cohesion' and '(lexical) collocation'. Evaluation of 14 conversations, 7 broadcast discussions and 7 phone calls, showed that the lexical cohesive items in the former corpus were almost six times as much as the latter. Gonzales argues that the difference can be related to the divergent features of these two genres. In addition to quantitative findings, qualitative analysis confirmed the crucial role of lexical cohesion in turn-taking behaviors and topic management patterns and consequently the expansion of generic stages in these two forms of oral interactions.

Buitkienè (2005) in her study investigated frequency and distribution of cohesive devices across registers. She analyzed three texts belonging to different registers, a legal text as a sample of a restricted register, a short story as an open-ended register, and a newspaper article somewhere in the middle of this continuum. The results revealed that lexical cohesive devices prevail in the texts belonging to different registers (Buitkiené, 2005). The researcher argues that distribution of different types of cohesive devices within the general framework is influenced by register. Furthermore, in closed register lexical cohesion priority over reference, ellipsis and substitution (Buitkienè, 2005).

Not many researchers have fathomed out specifically the application of lexical cohesive markers in literature context. Vyšniauskienè (2010) in her study of cohesive devices in English and Lithuanian literary texts explored the similarities and differences of their functioning in both languages. The results showed that the most widely used cohesive devices are lexical. Simple lexical repetition predominates in all texts. The distribution of simple repetition in the source text and target text was similar. In contrast, complex lexical repetition makes up the smallest part of cohesive devices in the texts. Moreover, more synonyms occurred in the target text in comparison to the source text. Antonyms were not used extensively. The distribution of meronymy was similar to hyponymy in texts. (Vyšniauskienè , 2010).

Among contrastive studies, the study done by Rahimi and Ebrahimi (2012) on lexical cohesion patterns in two English and two Persian novels based on the model proposed by Tanskanen (2006)might be a remarkable one. They found that selected Persian and English novel texts have different patterns of lexical cohesion caused by higher number of reiteration as well as collocation pairs used by Persian novelists. They asserted that similarities of these texts with regard to lexical relations had been more than their differences. (Rahimi, \&Ebrahimi, 2012).

As to the use of conjunctions, in the context of media, Ahangar, Taki, and Rahimi in a study (2012) investigated the functionality of conjunctions in Iranian sport live radio and TV talks based on Dooley \& Levinsohn (2001). According to Dooley \& Levinsohn, the conjunction contains four categories, including associatives, additives, adversatives, and developmental markers. Results showed that associatives were most frequently used while adversatives were the least. All in all in oral language more conjunction subtypes are used for more interactive communication. 
Hessamy and Hamedi (2013) in their study compared the frequency of the use of cohesive devices in independent and integrated essays written by 95 upper-intermediate Iranian EFL learners. The most-frequently used types of conjunctive cohesions in a descending order were additive, causal, temporal, adversative, and continuative conjunctive cohesions. The most frequently used type of conjunctive connector in both independent and integrated writings were the additive conjunction. Moreover, causal and temporal conjunctives were utilized comparatively more in the integrated writings than independent writings in this study.

Xin-hong (2012) in an experimental study, investigated the effect of cohesion theory on the teaching of writing to the Chinese graduate students. The researcher argued that the areas in which the most effect has been achieved seem to be "conjunction". In another study, Jo-Ling (2007) investigated college students' use of cohesive devices and the relationship between the number of cohesive features and writing quality. Among the five sub-categories of conjunction, additive devices had the largest percentage of use, followed by adversatives, causals, and temporals.

In translation research, Ketabi and Jamalv (2012) in their study explored the regular pattern of shifting conjunction devices from English into Farsi. They analyzed the similarities and differences of conjunctions between 40 English International Law texts (ELTs) and their Farsi translation texts (FTTs). The additive and adversative devices in parallel corpus accounted for over half of the total number of conjunctive ties. Both ELTs and FTTS shared more similarities than differences in the use of cohesive device of conjunction because of the informative function and stylistic features of law texts.

In the literary context, Shoghosho'ara (1996) examined differences in the application of conjunctions as a cohesive device in Persian stories at children and adults level. The findings revealed writers at both levels use all four kinds of conjunctions and that in both groups the frequency of additive conjunctions were higher than other conjunctions. Besides, the frequency of causatives in adult stories was twice as much as children's. The use of adversatives was almost the same in the corpus. Furthermore, temporal ones in children's stories were 2.5 times more than their adults' counterparts. It shows that, audience should be considered as an important element in writing stories.

In another research, Heslien (2012) in a part of her study analyzed conjunctions in three excerpts from Extremely Loud and Incredibly Close, a novel by Foer. The selected excerpts narrated from three points of view. The child character uses conjunctions to a greater extent than the grown up characters. Suswati.s, Sujatna. T.S, and Mahdi.s (2014) investigated different kinds of additive conjunctions, their semantic functions, and the unit of additive conjunction that constructed sentences in Four English Children Short stories written by Enid Blyton. The Result of their study showed that the simple additive relation was identified, namely; and (additive).

Finally, inthe child language studies, Ionescu (2011) in a research compared Romanian and English children and adult narrations with regard to cohesive elements of the stories. Results showed that the use of sequential connective markers increased with age. Also, it was found that the frequency of causal connectors decreased in both languages as children grew older and reached the lowest frequency in adults.

Cohesive devices play an essential role in producing and interpreting texts. Up to now, most of researches on English and specially literature have been done based on a contrastive analysis. Not many studies, as reviewed earlier, have analyzed fictional prose in a broader sense or compared it with other registers. Particular attention to this genre focused more on stylistic features. In the case of children literature, most of the studies have been done on the oral narratives produced by the children themselves. Fictional prose written for children as a good reflection of child- adult interactional discourse is not explored in this regard. More specially, lexical cohesion extensively used in authentic texts like the child discourse and literature, probably for its problematic and fluid nature is neglected by researchers.

Studies on conjunctions also most have been done on formal or productive texts and contexts. In this respect, a need exists to bridge the gap between discourse studies and less planned genres like fictions written for children. This study is an attempt to fill the gap in this regard. The main focus of this study is contrasting the use of lexical cohesion and conjunction in English novels written for children and adults. Due to the fact that the relationship between the open register and cohesive devices has not been thoroughly investigated from linguistic point of view, this study will investigate lexical cohesion -as an essential and influential factor in text cohesion and conjunctions as a grammatical cohesive device which is in direct relationship with age, in children and regular novels.

\section{Method}

\subsection{Corpus of the Study}

Two outstanding novels from British contemporary literature written by two great novelists constituted the material of study. The child novel was Danny the champion of the World by Roald Dahl, one of the most famous storytellers for children especially in Britain. The novel is set in the 1950s and written from the perspective of a nine years old boy. Danny's mother died when he was four months old, leaving him to be brought up by his father. Danny, and his father, William, live in a Gypsy caravan fixing cars for a living and partake in poaching pheasants and have a lot of fantastic adventures.

The novel selected as the regular fiction was Coming up for Air written by George Orwell famous for his great works Nineteen Eighty Four and Animal Farm. George Orwell is commonly considered as one of the most influential English writers of the 20th century, and as one of the most important historians of English culture of his generation. In Coming Up for Air, Orwell combines forebodings of the impending war with images of an idyllic Thames-side Edwardian 
era childhood. The novel is pessimistic, with its view that speculative builders, commercialism and capitalism are killing the best of rural England, "everything cemented over", and there are great new external threats.

Danny the Champion of the World, in common with Coming up for Air is more realistic among other works of authors. Both novels belong to 20th century and are narrated in first person and an autobiographical style and with a mannish insight to the world. However, one is told by a young boy and from an optimistic and positive view and the other (regular novel) narrated by a man of 45 years old with a pessimistic and informed view. All of these things made these two novels suitable choices for this study. In order to analyze a fair distribution of the sample, five chapters of each novel with different lengths and from different parts were selected as the sample of study. The corpus covers approximately 20 percent of each novel text based on the number of chapters and pages. Precise information on sample selection is reported in Table 1.

Table 1. The information of selected excerpts in the novel

Child novel

Regular novel

\begin{tabular}{cccccc}
\hline Chapter & $\begin{array}{c}\text { number of } \\
\text { Pages }\end{array}$ & $\begin{array}{c}\text { number of } \\
\text { Words }\end{array}$ & Chapter & $\begin{array}{c}\text { number of } \\
\text { pages }\end{array}$ & number of words \\
\hline 1 & 7 & 1018 & $1(4)$ & 4 & 2286 \\
\hline 5 & 9 & 1799 & $2(1)$ & 4 & 2784 \\
\hline 10 & 10 & 2044 & $2(5)$ & 5 & 2399 \\
\hline 14 & 13 & 2488 & $2(9)$ & 6 & 2790 \\
\hline 20 & 13 & 2326 & $4(2)$ & 7 & 3995 \\
\hline Total & 53 & 9675 & Total & 26 & 14254 \\
\hline
\end{tabular}

As shown in Table 1, the excerpts of the child novel (including 22chapters and 208 pages) were five chapters of the novel and considering full-page illustrations covered 53 pages of the whole. Chapter 1 and 2 as introductory chapters, chapters 10 and 14 as the body and chapter 20 as the concluding part provided the child text sample. The regular novel included four main parts. So from part one the first chapter among four, from second part (covering a great portion of the novel text) three chapters among ten, and from the last part second chapter and totally 26 of 236 pages were selected for analysis. The total number of words in the child novel was 40,021 and our sample included 9,675 words. The total number of words in the regular novel was 82,631, and 14,254 words were subject to codification. It should be mentioned that style as an indispensable part of writing was ignored in this study.

3.2 Codification Models

3.2.1 Model for Lexical cohesion codification

A further development of the original Halliday and Hasan model is that of Tanskanen (2006). Tanskanen views cohesion as a resource which communicators use to contribute towards coherence, hence the title of her monograph, Collaborating towards Coherence. Tanskanen's work is particularly interesting from a discourse point of view, because her model is developed in order to analyze cohesion in different text types. This comparative empirical purpose leads to a number of innovations into her model. She borrowed some of the categories from the previous models (e.g., Halliday and Hassan and Morris and Hirst (1991) and Hoey (1991)) and believed that her model "provided a good basis for understanding the work done by lexical cohesion in discourse" (Tanskanen, 2006, p.49). Tanskanen (2006) in her proposed model, first divides lexical cohesion into two main categories including reiteration and collocation and then defines eight subcategories for reiteration including Simple repetition, Complex repetition, Substitution, Equivalence, Generalization, Specification, Co-specification, and Contrast. Ordered-set, activity related and elaborative relations are three kinds of collocation in her model of lexical cohesion. This categorization is shown in Table 2.

Table 2. Lexical cohesion categories in the model proposed by Tanskannen (2006)

\section{Reiteration}

Collocation
1. Simple repetition
2. Complex repletion
3. Equivalence
4. Substitution
5. Generalization
6. Specification
7. Co-specification
8. Contrast

In this model, repetition is divided into simple repetition and complex repetition. Tanskanen (2006) asserted that simple repetition occurs when an item is repeated either in an identical form or with other no other than a simple grammatical change, e.g. singular-plural, present tense -past tense. Complex repetition involves a more substantial change. The item may be identical but serve different grammatical functions, or they may not be identical but share a lexical morpheme. The second category of reiteration in Tanskanen model (2006) is substitution. The most usual form of substitution is a pronoun substituting a noun. As Tanskanen (2006) notes that, following Hoey (1991), although pronouns are normally treated as part of grammatical cohesion, their function is very similar to full repetitions. So she included them in his 
classification. The third category of reiteration in this classification is Equivalence. Following McCarthy (1988), the term equivalence is used to refer to the relation more commonly referred to synonymy. For analyzing of the lexical relations a discourse -specific approach was adopted. As Tanskanen (2006) stated that the significance issue for this kind of approach to lexical relations is to take an item for instance in equivalence with another item, although they may not be semantically absolutely synonymous.

Generalization is the next kind of reiteration referred to the relationship between an item and a more general item. Specification is the fifth category is the opposite of generalization: It refers to an item and a more specific item. This item has previously been called meronymy and McCarthy referred to it as inclusion: general-specific (Tanskanen, 2006). The next subcategory of reiteration is co-specification which includes the relation between two items which have a common general item. In the earlier studies it has been referred as co hyponymy and co-meronymy. Finally, contrast corresponds to what in other systems is referred to as antonymy.

The second main category of lexical cohesion is collocation. This kind of relation between words always is an intrinsically controversial and notoriously to define so much so that, most of the times it has been excluded from analysis. In spite of all the difficulties in analyzing collocations they were included in lexical cohesion analysis. Ordered-set collocation includes members of ordered set of lexical items such as colors, numbers, months, and the days of the week and the like. The next kind of collocation which relates words to each other by means of an activity is called activity-related collocation. Elaborative collocation is association that neither can be considered as an orderedset nor as an activity-related collocation. It is defined based on frame theory. Frames are knowledge structures which are evoked by lexical items.

3.2.2 Model Used for Conjunction codification

The model of conjunction analysis applied for the study is the proposed one by Halliday and Matthiessen (2004). Elaboration, extension and enhancement have been identified as the main categories in this model. These items are illustrated in table 3 .

Table 3. Conjunction taxonomy proposed by Halliday and Matheson(2004)

\begin{tabular}{clll}
\hline Elaboration & Extension & Enhancement \\
\hline 1. Appositive & 1. Additive & 1. & Temporal \\
2. clarificative & 2. Adversative & 2. Comparative \\
& 3. Variative & 3. Causal \\
& & 4. Conditional \\
& & 5. Concessive \\
& & 6. Matter \\
\hline
\end{tabular}

Elaborating relation encompasses two subcategories, namely appositive and clarificative. Apposition serves to "represent" or "restate" an element by exemplifying, while clarification serves to summarize or to make the preceding text appear clearer or more specific (Halliday and Matthiessen, 2004). Extension has the subcategories addition and variation. Addition "expands" the text; it adds elements to the text using items that are classified as either positive (e.g. and, also ...), negative (nor), or adversative (e.g. but, however...), while variation introduces elements that are in some way presented as "alternatives" to what has gone before, and includes items that are either replacive (e.g. instead), subtractive (e.g. apart from that) or alternative (e.g. or (else), alternatively).

Enhancement includes those items that are used to show how the elements in a text relate to each other in terms of cause and effect, time and space or what has been discussed elsewhere in the text. The enhancement category has the subcategories spatio-temporal, manner, causal-conditional and matter. Spatio-temporal conjunctions marks spatiotemporal relations that exist both within the text (how the text unfolds in time) or in the outside world. These are known respectively as internal and external conjunctions.

Causal conjunctions can either be realized by items that have a general meaning (e.g. therefore, hence), or items that have more specific meanings that express result, reason or purpose. The conditional conjunctions can be positive, negative or concessive. According to Halliday and Hasan's (1976) view, some of the causal conditional conjunctions can also be seen as being either external or internal in that they can express both causal relations or conditions in the real world and causes and conditions that lay the premises for the line of argument that is being present in a given text (Halliday and Hasan 1976). Matter conjunctions create cohesion by linking an element in the text to what has been discussed earlier in the same text. Halliday and Matthiessen argue that "many expressions of matter are spatial metaphors, involving words like point, ground, field; and these become conjunctive when coupled with a reference items" (Halliday and Matthiessen 2004, p. 547).

3.3 Inter-coder reliability

Corpus of the study was coded by two skillful coders. The second coder took a sample of $25 \%$ of the corpus for codification. Cohen's Kappa measure of inter-coder reliability was used for calculating inter-coder reliability. The calculated results show approximately .90 agreements between the codifications which is quite an acceptable level. 
3.4 Data codification

Based on the model proposed by Tanskanen (2006) for lexical cohesion and that of Halliday and Mattheisson (2004) for conjunction codification, the occurrence of all kinds of lexical cohesion and conjunction was detected and their frequencies were calculated and recorded consequently. The lexical cohesion analysis is based on the concept of a cohesive pair, which is why three related items, for instance, will form two cohesive pair. Besides, both inter sentential and intra sentential cohesive relations were included in lexical cohesion rating. The third point is that in the codification of lexical items the whole chapter considered as the unit of codification. In the following part, some examples are provided for more illustration. (Lexical items are italicized and underlined but conjunctions are boldfaced)

...But, at that moment, $\underline{I}$ didn't feel like the life and soul of the party. And it struck me that nowadays $\underline{I}$ nearly always do have a orose kind of feeling in the early mornings, although I sleep well and my digestion's good. $I$ knew what $i t$ was, of course - it was those bloody false teeth. The things were magnified by the water in the tumbler, and they were grinning at me like the teeth in a skull. It gives you a rotten feeling to have your gums meet, a sort of pinched-up.

(Coming up for Air, p.1)

In this example from the regular novel, I.I; I-me and it was-it was and also feeling-feeling are samples of simple repetition. Besides, Feeling and feel make a complex repetition relation. It pronoun in third line and they in forth, substitute for "a morose kind of feeling" and "false teeth" respectively. Sleep and digestion are co-specifications of body activities. Good and well; morose and rotten are in equivalence. On the other hand, the former is in contrast with the latter. The teeth are generalized by things in forth line and then by Skull in the last line. Besides, gums and teeth are in an elaborative collocation.

Conjunction "But" is a kind of adversatives. In third line, "although 'is concessive. Conjunction "And"in the first line has additive function. Finally, "at the moment" and "in the early morning" are temporal devices.

4. Results of the study

In this section, the focus is on the distribution and variation of lexical cohesive relations in the chosen texts of the given novels and their potential similarities and differences in terms of different lexical categories. It should be mentioned that frequencies of cohesive pairs are normalized to a text of 1000 words, showing how many times they would occur in a text of 1000 words. Therefore, the numerical data is directly comparable which facilitate our findings comparison. It should be mentioned that since the data is basically nominal non-parametric test of Chi-square was used for further data analysis. Frequency of each category of cohesion was counted and tallied and for inferential data analysis.

To present a perfect image of codification procedure, raw figures and percentages are also expressed in the tables. Percentages also represent the ratio of frequency of each category to the total frequency of categories multiplied by 100. Table 4, shows the total number of different lexical categories in analyzed excerpts of selected novels.

Table 4. Frequencies of reiteration and collocation pairs in the child and regular novel texts.

\begin{tabular}{|c|c|c|c|c|c|c|c|}
\hline & & \multicolumn{3}{|c|}{ Child novel } & \multicolumn{3}{|c|}{ Regular novel } \\
\hline & & $\mathrm{F}$ & $\mathrm{NF}$ & PCT & $\mathrm{F}$ & NF & PCT \\
\hline \multirow{9}{*}{ 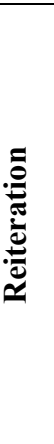 } & Simple repetition & 1774 & 183 & $60 \%$ & 2576 & 181 & $66 \%$ \\
\hline & Complex repetition & 76 & 8 & $3 \%$ & 80 & 6 & $2 \%$ \\
\hline & Substitution & 223 & 23 & $8 \%$ & 270 & 19 & $7 \%$ \\
\hline & Equivalence & 171 & 18 & $6 \%$ & 190 & 13 & $5 \%$ \\
\hline & Generalization & 79 & 8 & $3 \%$ & 96 & 7 & $3 \%$ \\
\hline & Specification & 149 & 15 & $6 \%$ & 126 & 9 & $3 \%$ \\
\hline & Co-specification & 63 & 7 & $2 \%$ & 79 & 5.5 & $2 \%$ \\
\hline & Contrast & 72 & 7 & $2 \%$ & 78 & 5 & $2 \%$ \\
\hline & Total & 2607 & 269 & $90 \%$ & 3495 & 245 & $90 \%$ \\
\hline \multirow{4}{*}{ ن } & Ordered set & 30 & 3 & $1 \%$ & 37 & 3 & $1 \%$ \\
\hline & Activity related & 129 & 13 & $5 \%$ & 174 & 12 & $5 \%$ \\
\hline & Elaborative & 116 & 12 & $4 \%$ & 171 & 12 & $4 \%$ \\
\hline & Total & 275 & 28 & $10 \%$ & 382 & 27 & $10 \%$ \\
\hline
\end{tabular}

Note: F: frequency, NF: normalized frequency, PCT: percentage

As shown in Table 4, the dominant category in both child and regular novel is simple repetition. Substitution comes second and equivalence was the third frequent type in both novel texts. Child and regular novel texts were closely similar with regard to the frequency of the simple repetition, generalization, contrast, co-specification, complex repetition, and collocation categories. The most striking difference between two novels concerning the frequency of lexical cohesion pairs was related to specification category.

The frequency of specification pairs in child novel was nearly two times as much as its counterpart in regular novel. Equivalenceand substitution pairs are also less frequent in regular novel compared to the child. Moreover, reiteration relations are more frequent both in the child and regular novels. The two selected novel seemed to differ in terms of 
total frequency of reiteration pairs; overall, child novel, showed relatively higher normalized frequency of reiteration as well as collocation pairs than the regular one.

4.1 Result of Chi square test for lexical cohesive devices

In order to examine the significance of difference between analyzed texts of child and regular novel in terms of different lexical cohesive devices, Goodness of fit Chi square tests were performed. Table 5 shows the result of chi square test for reiteration and collocation and total number of lexical cohesive ties in both novels.

Table 5. Results of Chi square test for two main categories of lexical cohesion in child and regular novel

\begin{tabular}{|c|c|c|c|c|c|c|}
\hline & & Child novel & Regular novel & Chi value & Df. & $\mathrm{P}$ (value) \\
\hline \multirow{2}{*}{ Reiteration } & Exp. & 2607 & 3495 & \multirow{2}{*}{64.61} & \multirow{2}{*}{1} & \multirow{2}{*}{$<0.00001$} \\
\hline & Obs. & 3051 & 3051 & & & \\
\hline \multirow{2}{*}{ Collocation } & Exp. & 275 & 382 & \multirow{2}{*}{8.71} & \multirow{2}{*}{1} & \multirow{2}{*}{0.003165} \\
\hline & Obs. & 328.5 & 328.5 & & & \\
\hline \multirow{2}{*}{$\begin{array}{l}\text { Total of Lexical } \\
\text { Cohesive Pairs }\end{array}$} & Exp. & 2882 & 3877 & \multirow{2}{*}{73.23} & \multirow{2}{*}{1} & \multirow{2}{*}{$<0.00001$} \\
\hline & Obs. & 3379.5 & 3379.5 & & & \\
\hline
\end{tabular}

As shown in table 5, results of Chi square test for two main categories of lexical cohesion in the child and the regular novel show that these two novels are significantly different concerning frequency of reiteration and collocation cohesive pairs. Obtained Chi square value for total frequency of lexical cohesive pairs is so much higher than the critical value at significance level of 0.05 . Besides, relevant $\mathrm{P}$ (value) is less than the 0.05 level of significance. Consequently, the difference between child and regular novel regarding total frequency of lexical cohesive relations is significant.

4.2 Results of conjunction codification

The same steps were taken to document conjunctions analysis data. Table 6 compares the child and regular novel texts based on the frequencies of three main categories of conjunctions in raw, normalized and percentage forms.

Table 6. Frequencies of three main categories of conjunction in the child and regular novel texts

\begin{tabular}{ccccccc} 
& \multicolumn{3}{c}{ Child novel } & \multicolumn{3}{c}{ Regular novel } \\
\cline { 2 - 7 } & $\mathrm{F}$ & $\mathrm{NF}$ & $\mathrm{PCT}$ & $\mathrm{F}$ & $\mathrm{NF}$ & PCT \\
\hline Elaboration & 23 & 2 & $6 \%$ & 75 & 5 & $12 \%$ \\
\hline Extension & 98 & 10 & $25 \%$ & 235 & 16 & $37 \%$ \\
\hline Enhancement & 265 & 27 & $69 \%$ & 314 & 22 & $51 \%$ \\
\hline Total & 386 & 39 & $100 \%$ & 624 & 43 & $100 \%$ \\
\hline
\end{tabular}

As shown in Table 6, enhancement is the most frequent category in both child and regular novels and Extension comes next. Based on normalized frequencies, there are about 27 and 22 enhancing markers (i.e., temporal, comparative, causal, conditional and concessive) in the child and regular novel texts respectively. The total number of extending markers (including additive, adversative and variative) is 10 for child novel and 16 for regular novel. Elaboration (appositive and clarificative) has the lowest frequency among three. Seemingly, child and regular novel texts differs in the use of these three main categories of conjunction. Besides, elaboration as well as extension is more frequent in regular novel. Yet, enhancement has higher extent of application in the child novel texts. Detailed comparison of different lexical cohesion ties in sample texts is reported in Table 7.

Table 7. Relative comparison of the child and regular novel texts based on different subcategories of conjunction

\begin{tabular}{|c|c|c|c|c|c|c|c|}
\hline & & $\mathrm{F}$ & NF & PCT & $\mathrm{F}$ & $\mathrm{NF}$ & PCT \\
\hline \multirow{3}{*}{ Elaboration } & Appositive & 0 & 0 & $0 \%$ & 9 & 1 & $1 \%$ \\
\hline & Clarificative & 23 & 2 & $6 \%$ & 66 & 5 & $11 \%$ \\
\hline & Total & 23 & 2 & $6 \%$ & 75 & 6 & $12 \%$ \\
\hline \multirow{4}{*}{ Extension } & Additive & 50 & 5 & $13 \%$ & 145 & 10 & $23 \%$ \\
\hline & Adversative & 41 & 4 & $11 \%$ & 67 & 5 & $11 \%$ \\
\hline & Variative & 7 & 1 & $2 \%$ & 23 & 2 & $4 \%$ \\
\hline & Total & 98 & 10 & $26 \%$ & 235 & 17 & $38 \%$ \\
\hline \multirow{7}{*}{ Enhancement } & Temporal & 185 & 19 & $48 \%$ & 213 & 15 & $34 \%$ \\
\hline & Comparative & 15 & 1.5 & $4 \%$ & 18 & 1 & $3 \%$ \\
\hline & Causal & 42 & 4 & $11 \%$ & 36 & 2.5 & $6 \%$ \\
\hline & Conditional & 6 & 1 & $1 \%$ & 3 & 0 & $0 \%$ \\
\hline & Concessive & 17 & 2 & $4 \%$ & 44 & 3 & $7 \%$ \\
\hline & Matter & 0 & 0 & $0 \%$ & 0 & 0 & $0 \%$ \\
\hline & Total & 265 & 27.5 & $68 \%$ & 314 & 21.5 & $50 \%$ \\
\hline
\end{tabular}


As reported in Table 7, the most frequent category of conjunctions in both child and regular novel is temporal; additive comes next. The descending order of frequency for other categories in the child novel is causal, adversative, clarificative, concessive, comparative, variative and conditional. The same rank order of regular novel is adversative, clarificative, concessive, causal, variative, comparative, appositive, and conditional. The category of Matter is absent in the child as well as regular novel texts under the study. Also, appositives are not observed in the child novel texts.

According to the normalized frequencies, the most obvious difference between child and regular novels concerning conjunctions is related to additive and clarificative categories. Frequency of additive and clarificative conjunctions in the regular novel is about two times more than the child novel. Both novels are closely similar with regard to adversative conjunctions. Temporals, comparatives, and causals are more frequent in the child novel. Conditional conjunctions, although rare in the data, were found more in the selected child texts. Besides, concessives and variatives are less frequent in the child novel compared to the regular.

4.2.1 Results of Chi square test for different types of conjunctions

Chi square test also performed to determine the significance of difference for conjunctions.

Table 8 represents Chi square values for three main categories of conjunction and total number of them in the novels.

Table 8 . The results of Chi square test for three main categories of conjunction in the child and the regular novel texts.

\begin{tabular}{|c|c|c|c|c|c|c|}
\hline & & Child novel & Regular novel & Chi value & Df. & $\mathrm{P}$ (value) \\
\hline \multirow{2}{*}{ Elaboration } & Exp. & 23 & 71 & \multirow{2}{*}{12.25} & \multirow{2}{*}{1} & \multirow{2}{*}{0.0004} \\
\hline & Obs. & 47 & 47 & & & \\
\hline \multirow{2}{*}{ Extension } & Exp. & 98 & 235 & \multirow{2}{*}{28.18} & \multirow{2}{*}{1} & \multirow{2}{*}{$<0.00001$} \\
\hline & Obs. & 166.5 & 166.5 & & & \\
\hline \multirow{2}{*}{ Enhancement } & Exp. & 265 & 314 & \multirow{2}{*}{2.07} & \multirow{2}{*}{1} & \multirow{2}{*}{0.15} \\
\hline & Obs. & 289.5 & 289.5 & & & \\
\hline \multirow{2}{*}{$\begin{array}{l}\text { Total No. of } \\
\text { Conjunctions }\end{array}$} & Exp. & 418 & 618 & \multirow{2}{*}{19.30} & \multirow{2}{*}{\multicolumn{2}{|c|}{$1<0.00001$}} \\
\hline & Obs. & 518 & 518 & & & \\
\hline
\end{tabular}

As reported in Table 8, Chi square values related to elaboration and extension categories exceed the critical value (3.84) at significant level of 0.05 . This reveals that the child and regular novel texts are significantly different in terms of elaboration and extension. However, difference between child and regular novel with regard to the frequency of enhancement is not meaningful. Chi square value for total number of conjunctions is 19.30 , higher than the critical value, and $\mathrm{P}$ is $<0.000(<0.05)$. Hence, the conditions are ideal asserting that difference between the child and regular novel texts regarding total frequency of conjunctions is statistically significant.

\section{Discussion}

Among all lexical cohesive markers, simple repetition, substitution and equivalence were the most frequent subtypes in both child and regular novel. Obviously, simple repetition is the steadiest way of pointing to a particular referent, so, its frequency of occurrence in both child and regular novel is naturally higher than other kinds. Also according to the very nature of narrative discourse, to avoid ambiguity on behalf of the reader, a constant shift occurs between pronouns and their referents. Equivalence or, as referred in previous studies, synonymy, known as the best alternative for avoiding simple repetition in narrative genre.

According to comparative results, the normalized frequencies of all categories, except for specification, were relatively similar in both child and regular novel texts. As Tanskanen argued (2006), it can be related to the two texts similarity in their communicative purposes. Striking difference between child and regular novel was related to specification category. Its frequency in the child novel was reported about two times more the regular novel. Due to the fact that child novel was a picture book, writer attempts to elaborate story's location in time and place, create moods, provide an antagonist along with illustrations. As a result, more specification and whole-part relations are observed in this kind of fictions compared to the regular ones. On the other hand, Concreteness and reference to concrete objects for signaling the mental concepts also are very characteristic of child language.

The more dialogic structure of child novel and the multitude of referents in that can be responsible for more frequency of substitution in this novel compared to the regular. Also more frequency of simple and complex repetition and equivalence ties in the child novel can be partly related to the audience needs and partly to novelist's lexical and literally preferences. Results of Chi square, however, showed that both child and regular novels are significantly different with regard to the frequency of both reiteration and collocation categories and further total number of lexical cohesive pairs. One explanation for that can be the more lexical density in the regular novel compared to the child one. Also from a psycholinguistic point of view, paradigmatic inclination in adult associative responses rather than the syntagmatic tendency in children can be another justification.

The present study was, in some respects, analogues with the study of Rahimi and Ebrahimi (2012) on English and Persian novels. As a result of their pervasiveness in narrative prose, simple repetition and substitution respectively were the most frequent kinds of lexical cohesion in both corpora and ordered- set collocation was the least. The most obvious difference between two corpora is related to equivalence. It was the third most frequent category in the present study, but the least one (after generalization) in English novels of Rahimi and Ebrahimi (2012). It is probably related to the lexical pattern choices by writers. 
Besides, in accordance with the studies of Rahimi and Ebrahimi (2012) as well as Tanskanen (2006), the results of present study indicate that collocation (as a whole) is relatively much less effective than the reiteration as a cohesive feature.Due to the fact that collocation pairs (more especially elaborative and ordered -set) are fixed relations between words, they cannot be used as extensively as reiteration pairs.

Synonymy and meronymy, contrary to the present study, werethe least used sub categories in English and Persian abstracts of Iranian medical students' theses (seddigh, Shokrpour and Kafipour (2009)). Besides, result of Mirzapour and Ahmadi study (2011) in the case of English articles (of linguistics and literature) showed that they used collocation much more than synonymy as well. In narrative genres, as seen in the case of the short stories in Vyšniauskiene (2010) and Buitkiene (2005) studies and the novels of present study, equivalence (or synonymy) takes the priority over the other items. Also in legal and newspaper genres in Buitkiene (2005), meronymy has the lowest frequency.

Accordingly, it can be cautiously deducted that synonymy and meronymy implying a degree of ambiguity are not extensively used in academic, legal and news stories and are more typical in fiction. Simple repetition was also the common feature of this study with Kai (2008). However, Substitution, the second most frequent category in the present study, was the least one in Kai (2008). On the other hand, complex repetition, the second one in the NSs abstract (in Kie (2007) and the rare in present corpora. The legal text in Buitkiene (2005) also shows a high frequency of complex repetition. Therefore, Complex repetition seems to be more pervasive in academic and other formal texts. Hence, texts of different genres may to some degree influence the frequency of lexical choices.

As to the use of conjunctions, temporals as well as additives contribute to thematic development in a narrative prose, so they were the most frequent subtypes in analyze data. However, more dynamic theme of the child novel, results in higher range of temporality in that, compared to the regular. The most obvious difference between child and regular novels concerning conjunctions was related to additives and clarificatives. Conjunction 'and' was the most frequent form of additives which, as discussed earlier, can function as a temporal as well. In child novel, temporal 'and' as well as 'and then' take a fair share of data and maybe outnumbered the additive ones. In child language development also these two terms are used extensively to make a sequential order in utterances. In regular novel with its static line of story most of the ands were employed to present additional information so, the regular novel had more frequency of additives. Furthermore, Clarificatives, because of their formal structure, are much more pervasive in texts written for grown-up audience. As a result, elaboration and extension categories show a meaningful difference between the child and regular novel texts as to the use of conjunctions.

It is compatible with the fact that adults took a more literary approach when narrating the story which Berman and Slobin (1994) call 'bookish story telling' (cited in Ionescu, 2011).Frequency of enhancement including temporal markers showed no significant difference between the child and regular novels. Since the child novel is told by a9 years old - child, and that children gradually develop their understanding of temporal sequence during school years, the similarity of both novels in the use enhancement is justifiable. Adversative markers (usually but) had been distributed equally in both child and regular novels. It is in accordance with the fact that adversatives are perceives as the conjunctions from early ages (Mcclure and Geva, 1983 and Peterson, 1983). The rarity of Matter, appositive, and conditional in the child and regular novel texts under the study is due to their pervasiveness in academic and scientific texts. Overall, more frequent use of conjunctions, as a whole, in the regular novel compared to the child novel confirms the previous findings on child language development (Berman and Slobin ,1994; Hickmann, 2003) that by getting older making logical connections evolved.

The results of present study can be compared with those of a similar work on Persian literature by Shoghosho ara (1996). With regard to the use of adversative, both researchers report the same results. The use of adversatives in child and adult novels was almost the same in both English and Persian corpora. As stated earlier, adversatives are perceived as conjunctions by children in early ages, so, the given similarity may be reasonable in Persian as well as English. As another common point, temporals in both studies (on Persian and English stories) were more frequent in child novel compared to the adult one. It can be related to the occurrence of more sequential clauses in child novel compared to the regular, as mentioned earlier. The difference between frequency of this category in English child and adult novels, unlike their Persian counterparts was not significant nevertheless. It can be related to more sequentially organized structure of the selected English novels compared to the Persians. Furthermore, in Persian study the additive was the dominant category while in the present study, temporal was the most frequent and additive came next. It is also justifiable based on the dynamic structure of selected novels. Based on Halliday and Mattheisson (2004) model for conjunction, as another explanation it can be said that in the present study, temporal 'ands' were employed and considered as well as additive ones.

The most obvious difference between this study and Soghosh'ara one is related to the frequency of causal category. Causals in our study occurred more in child novel but in the Persian novels studied by Shoghosho ara were more frequent in novels for adult level. It probably related to different linguistic priorities of English and Persian novelists and can be a case for further investigation.

Also, the study supports the findings of Ioana Daciana's (2011) study which showed that children gradually develop their understanding of temporal sequence during school years and adults employed more specific forms of temporal sequencing than children and that the of employment of causal connectors decreased in both languages as children grow older and reached the lowest frequency in adults (Ioana Daciana, 2011).The study also has something in common with the study by Ahangar et al. (2012). In both corpora (novels and Iranian sport live TV and Radio talks) additives came second in terms of frequency. It can be due to the less formality in both genres and then the use of less formal 
conjunctions like additives. And in accordance with TV talks, in present study the regular novel employed adversative as a third device to create cohesion. It might be related again to less planned structure in both sets with relation to their audience.

However, compared with legal texts (the ones studied by Ketabi and Jamalvand (2012)) differences are more than similarities. The most obvious difference is related to the temporal conjunctions. Temporals were the most frequent kind of conjunction in our data but the least ones in legal corpora. It can be due to the fact that narrative prose is in direct relation with the frequency of temporal conjunctions in this context. In the legal corpora, adversatives were the most frequent kind of conjunctions. It is also related to their basic function in legal text to 'draw conclusions', 'present or explain information 'and 'make contrasts'. Besides, due to their less functionality in narrative discourse, adversatives (after temporals and additives) were the third device used in the regular novel. Additives in the legal and fictional texts were the second frequent kind of conjunctions, 'used to illustrate the propositions', 'add information' and 'substantiate ideas'. In legal corpora causals were the third frequent ones.

\section{Conclusion}

This study was an attempt to find the similarities and differences between novels for children and adult level with regard to the use of different lexical cohesive markers and conjunctions and to find if there is a significant difference between them. To fulfill this aim, selected experts of two contemporary novels, were analyzed and rated in this regard. The analysis was based on proposed model by Tanskanen (2006) for the lexical cohesion and that of Halliday and Mathiessen (2004) for conjunction. As to the use of lexical cohesive marker, simple repetition, substitution and equivalence in a descending order were the most frequent categories in both novels. The child corpus exceeded the regular data in the use of these three sub-types. Furthermore, the result of Chi square test showed that the selected novels were significantly different regarding the employment of two main categories of lexical cohesion (reiteration and collocation) as well as total number of lexical cohesive pairs. Concerning the use of conjunctions, temporals were the most frequently used sub-type of conjunctions, followed by additives. Obtained results of Chi square tests for conjunction revealed that the application of elaboration and extension showed a meaningful relation in the child and regular corpora. In addition, conditionals were the least used sub-type of conjunctions. So, it can be concluded that they do not play a significant role in making the novels cohesive. Finally, It should be noted that this study focused, for the most part, on the 'what' aspect of the issue rather than the 'why' aspect. Therefore, while we have to exercise caution in drawing absolute conclusions about similarities and differences between the child and regular novels in terms of lexical cohesion and conjunction, simply based on the findings from the present study, the results of this study could be illuminating and might have various implications and applications.

Lexical cohesion is helpful in a range of areas such as translation studies, computational linguistics, information retrieval researches and teaching and learning. Cognitive structure of a reader can be influenced by various lexical cohesive strategies and translators should be aware of them to do an accurate job. Lexical cohesion is also of great importance in Preparing summaries and also dev texts into thematically coherent units. And obviously it can be useful for language teachers, students and material developers. Employing authentic sources of languages especially fictional narrative texts might be fruitful for teaching vocabulary and improving writing, reading and even speaking skills in a discourse based approach. Collocation and equivalence relations specially can be learned more easily by means of assignments asking learners to detect them in a fictional prose. This serves to enlarge learner's vocabulary and consequently improves their argumentative and academic writings in future. Conjunctions are also problematic devices for EFL learners. Knowing most frequently used kinds of conjunction in English children novels as well as linking strategies in regular novels that make them enjoyable for their audience, may give a good insight to employ them in a discourse based approach. Generally speaking, Explicit or implicit awareness of cohesive markers in authentic sources of language facilitates the learning process to a great extent.

It is evident that investigation of the other cohesive devices including reference, substitution and ellipsis would give a deeper insight in terms of textual cohesion. Besides, data collection, especially different kinds of lexical cohesion was a time-consuming task, so, as a solution, data analysis limited to some excerpts of selected novels text. Expansion of the material will add to the accuracy of the obtained results. Regarding the broadness of children literature range, inter and intra linguistic studies on science books, magazines for and about children and in terms of lexical cohesion and coherence will be fruitful in teaching and material development. Investigating lexical cohesive devices in oral and written children narratives alone or in comparison with adult narratives would be of great significance and give a great depth to vocabulary teaching and learning strategies. Virtual and real Spontaneous utterances are great contexts for study as well.

\section{References}

Ahangar, A, Taki. G., \& Rahimi. M. (2012). The Use of Conjunctions as Cohesive Devices in Iranian Sport Live Radio and TV Talks, Journal of Theoretical Linguistics [online] 9(2), 56-72.

Bennet-Kastor, T. L. (1986). Cohesion and Predication in Child Narrative. Journal of Child Language, 13, 353370.

Berman, R. A. \& Slobin, D. I. (1994). Different ways of relating events in narratives: A Cross linguistic Developmental study. Hillsdale, NJ: Lawrence Erlbaum.

Buitkienè. J. (2005). Variability of Cohesive Devices across Registers. Studies about Languages 7, 17-20. 
Casado V., M. (1997). Introducción a la gramáticadeltexto del español. Madrid: Arco.

Coulthard, M. (1994). Advances in Written Text Analysis. London: Routledge Flowerdew.J,(2013). Discoursein English Language Education. London and New York: Rutledge.

Fazl-Ali, F. (1995). The analysis of ellipsis in Persian. Unpublished MA thesis: AllamehTabatabayi University.

Gutwinski, W. (2007). Cohesion in Literary Texts. The Hague: Mouton.

Halliday, M. A. K., \& Hasan, R. (1976). Cohesion in English. London: Longman.

Halliday, M. A. K. (1985). An Introduction to Functional Grammar, London: Edward Arnold.

Halliday, M. A. K., \& Mathiessen, C. (2004). An Introduction to Functional Grammar (3 ${ }^{\text {th }}$ Eds). London: Edward Arnold.

Hasan, R. (1984). Coherence and Cohesive Harmony. In J. Flood (Ed.), Understanding Reading Comprehension Delaware: International Reading Association.

Heslien.P.S.A. (2012) Cohesion, Style and Narrative in Foer's Extremely Loud and Incredibly Close. M.A. Thesis. University of Oslo.

Hessamy. G. R., \&Hamedi.S. (2013). A Comparison of the Use of Cohesive Devices in EFL Learners' Performance on Independent vs. Integrated Writing Tasks. Study in English Language Teaching 1(1), 121-146.

Hickmann, M. (2003). Children's Discourse: Person, Space and Time across Languages. Cambridge, UK: Cambridge University Press.

Hyland, K. (2005). Metadiscourse: Exploring Interaction in Writing. London: Continuum.

Ioana Daciana, I. (2011). Cohesion and Coherence in Narratives: A Cross-linguistic Analysis in English and Romanian.MA thesis. San Diego State University.US.

Jo-Ling, C. (2007). An investigation of EFL students' use of cohesive devices. Retrieved from http://nutnr.lib.nutn.edu.tw/bitstream/987654321/7773/1/07.

Kachroo, B. (1984). Textual Cohesion and Translation. Meta, 29, 2.

Kai, J. (2008). Lexical Cohesion Patterns in NS and NNS Dissertation abstracts in Applied Linguistics: A comparative study. Retrieved Dec. 7, 2009, from http://www.linguistics-journal.com/December_2008-ik.php.

Kavoosinejad, Z.(1993). Ellipsis in Persian. Unpublished MA thesis: Tehran University.

Ketabi. S, \& Jamalv A. A. (2012). A Corpus-based Study of Conjunction Devices in English International

Law Texts and its Farsi Translation. International Journal of Linguistics 4(4), 362-72.

Lee, J. (2013).The Application and Significance of Discourse Cohesion and Analysis in Practical Teaching of Foreign Language. Theory and Practice in Language Studies 3(8), 1393-1398.

MacMillan, F. (2007). The Role of Lexical Cohesion in the Assessment of EFL Reading Proficiency. Arizona Working Papers in SLA and Teaching14, 75-93.Mcclure. E, \&Geva. E. (1983). The Development of the Cohesive Use of Adversative Conjunction in Discourse. Discourse Processes 6,411-432.

Mcclure, E. \& Geva, E. (1983). The Development of the Cohesive Use of Adversative Conjunction in Discourse. Discourse Processes 6,411-432.

Medereos Martin, H. (1988). Procedimientos de cohesiónen el español actual Aula de Cultura, Tenerife.

Mirzapour, F. \& Ahmadi, M. (2011). Study on lexical cohesion in English and Persian research articles:A Comparative study. English Language Teaching 4, 4, 245-253, doi:10.5539/elt.4,4,245.

Morris, J. \& Hirst, G.(1991). Lexical cohesion computed by thesaural relations as an indicatorof the structure of text, Computational Linguistics.

Noormohammadi, E. (1988). A Contrastive Analysis of Cohesion in English and Persian Unpublished MA thesis: Shiraz University.

Oshima, M. (1988). A comparative Discourse Analysis of English and Japanese. Occasional Papers. Applied Linguistics Association of Australia, 10,194-202Peterson, C. (1986). Semantic and pragmatic uses of 'but'. Journal of Child Language 13, 583-90.

Parsons, G. (1996). The Development of the Concept of Cohesive Harmony. In M. Berry C.Butler, R. Fawcett, G. Huang (Eds.), Meaning and Form: Systemic Functional Interpretations Meaning and Choice in Language: Studies for Michael Holliday, Ablex, Norwood, NJ.

Peterson, C. (1986). Semantic and pragmatic uses of 'but'. Journal of Child Language 13, 583-90.

Rahimi, A. \& Ebrahimi, A.N. (2012) Lexical Cohesion in English and Persian Texts of Novels. Mediteranian Journal of Social Sciences (3).

Roberts, J. R., Barjasteh D., \& Jahani, C. (2009). A Study of Persian Discourse Structure. Uppsala: Uppsala University.

Seddigh, F., Shokr-pour, N., \& Kafipour, R. (2010). Lexical cohesion in English and Persian Abstracts. Iranian Journal of Applied Language Studies, 2(1), 157 -168. 
Shoghosho'ara, L. (1996). The Analysis of Cohesion Relations in Adults and Children's Stories. Unpublished M. A. Dissertation: Tehran University.

Simmons, C. (1981). Cohesion in Russian: a model for Discourse Analysis. Slavic and East European Journal 25(2), 345-347.

Stotsky, S. (1983). Types of Lexical Cohesion in Expository Writing: Implications for Developing the Vocabulary of Academic Discourse. College Composition and Communication 34(4), 430-446.

Suswati.s, Sujatna.T. S, \& Mahdi.S. (2014) Additive Conjunction Choice in English children Short Stories: a syntactic and semantic analysis. International Journal of Language Learning and Applied Linguistics World (IJLLALW) 5(4), 1121.

Tanskanen, S. K. (2006). Collaborating Towards Coherence: Lexical Cohesion in English Discourse. Amsterdam: Benjamin

Tseng, Y., \& Liou, H. (2006). The Effects of Online Conjunction Materials on College EFL Students Writing. System 34(2), 270-283.

Vyšniauskienè. R. (2010). Cohesive Devices in the Opening Paragraphs of Short Stories in English and Lithuanian. MA Paper. Vilnius University. Lithuania.

Xin-hong. Z. (2007).Application of English Cohesion Theory in the Teaching of Writing to Chines Graduate Students. 4, 7, US-China Education Review, ISSN1548-6613, USA.

Yang, W., \& Sun, Y. (2012). The Use of Cohesive Devices in Argumentative Writing by Chinese EFL Learners at Different Proficiency Levels. Linguistics and Education, 23(1), 31-48.

Zhang, D. L., \& Liu, R. S. (2003). The Development of the Theory of Text Coherence and Cohesion and its Application. Shanghai: Shanghai Foreign Language Education Press.

Zhu, Y. S., Zheng, L. X., \& Miao, X. W. (2001). A contrastive study of cohesion in English and Chinese. Shanghai: Shanghai Foreign Language Education Press. 